\title{
REVIEW
}

\section{Genetic Improvement in Juglans mandshurica and Its Uses in China: Current Status and Future Prospects}

\author{
Shikai Zhang ${ }^{1,2}$, Wang Zhan ${ }^{3}$, Heng Zhang ${ }^{1,2}$, Shuanglin Song ${ }^{3}$, Xibin $\mathbf{Q u}^{3}$, Jiayi Wang ${ }^{3}$, \\ Mulualem Tigabu ${ }^{4}$, Xiang $\mathrm{Li}^{1,2}$, Qinhui Zhang ${ }^{1,2}$, Minghui Zhao ${ }^{1,2}$, Huanzhen Liu $^{2, *}$ and \\ Xiyang Zhao ${ }^{1,2, *}$ \\ ${ }^{1}$ College of Forestry and Grassland, Jilin Agricultural University, Changchun, 130118, China \\ ${ }^{2}$ State Key Laboratory of Tree Genetics and Breeding, School of Forestry, Northeast Forestry University, Harbin, 150040, China \\ ${ }^{3}$ Baishishan Forestry Bureau, Jiaohe, 132500, China \\ ${ }^{4}$ Southern Swedish Forest Research Centre, Swedish University of Agricultural Sciences, Alnarp, SE-230 53, Sweden \\ *Corresponding Authors: Huanzhen Liu. Email: zhenzhen_0522@163.com; Xiyang Zhao. Email: zhaoxyphd@163.com \\ Received: 16 July 2021 Accepted: 14 September 2021
}

\begin{abstract}
Juglans mandshurica is an economically and ecologically valuable species that is used for various construction purposes, making luxurious furniture, as food and sources of medicinal substances and landscaping because of its excellent wood, edible fruits and rich in various types of chemical compounds. In the past few decades, several genetic improvements of $J$. mandshurica were made, with a focus on the selection of improved varieties and on breeding technology. Many elite provenances and families were selected based on growth traits or wood properties. In recent years, with the increasing demand for high-quality seedlings in Chinese forestry production, the breeding goals of genetic improvement for J. mandshurica were redefined to include other traits, such as fruit yield and contents of medicinal component. However, the improvement processes were still slow due to the long breeding cycle and the limited use of advanced breeding technologies, resulting in the selection of fewer improved varieties. In this review, we summarized the research progresses on genetic improvements of J. mandshurica and other related works, and discussed research gaps and suggested future directions for genetic improvement of the species. The review provides valuable insight for the selection of improved varieties and production of excellent germplasms.
\end{abstract}

\section{KEYWORDS}

Juglans mandshurica; breeding advances; genetic improvement; improved variety

\section{Introduction}

Juglans mandshurica, known as Manchurian walnut or northeast walnut, belongs to the genus Juglans (Juglandaceae). It is one of the famous "three-hardwood species" (the other two are Fraxinus mandshurica Rupr. and Phellodendron amurense Rupr.), and is distributed widely in Northeast China [1-3]. $J$. mandshurica is monoecious [4] and has extremely fast and luxuriant growth, with a thick, straight trunk that can reach 30 meters in height and $40 \sim 80 \mathrm{~cm}$ in diameter at breast height (DBH) under natural conditions. The detailed growth characteristics of $J$. mandshurica are shown in Fig. $1[5,6]$. This species 
can be used as an excellent grafting rootstock to graft other kinds of Juglans species [7]. Moreover, it produces good quality timber in forest plantations because of its excellent wood traits and fast growth rate [8,9]. It is also used as food supplements due to its edible dried fruits with high nutritional content [10]. More importantly, the green peel, leaves, bark and other tissues of $J$. mandshurica can be used for medicinal purposes and have been used in the development of traditional medicines [11]. At present, studies on medicinal component have found that triterpenoids [12,13], flavonoids [14,15], quinones [16] and other compounds contained in $J$. mandshurica have great effects in treating cancer, lowering blood lipids and exert antioxidative, anti-inflammatory and other effects. Unfortunately, the wild germplasm resources of $J$. mandshurica declined seriously in the past few decades. Large numbers of trees were overharvested because of the increasing wood price and lack of protection policies [17].
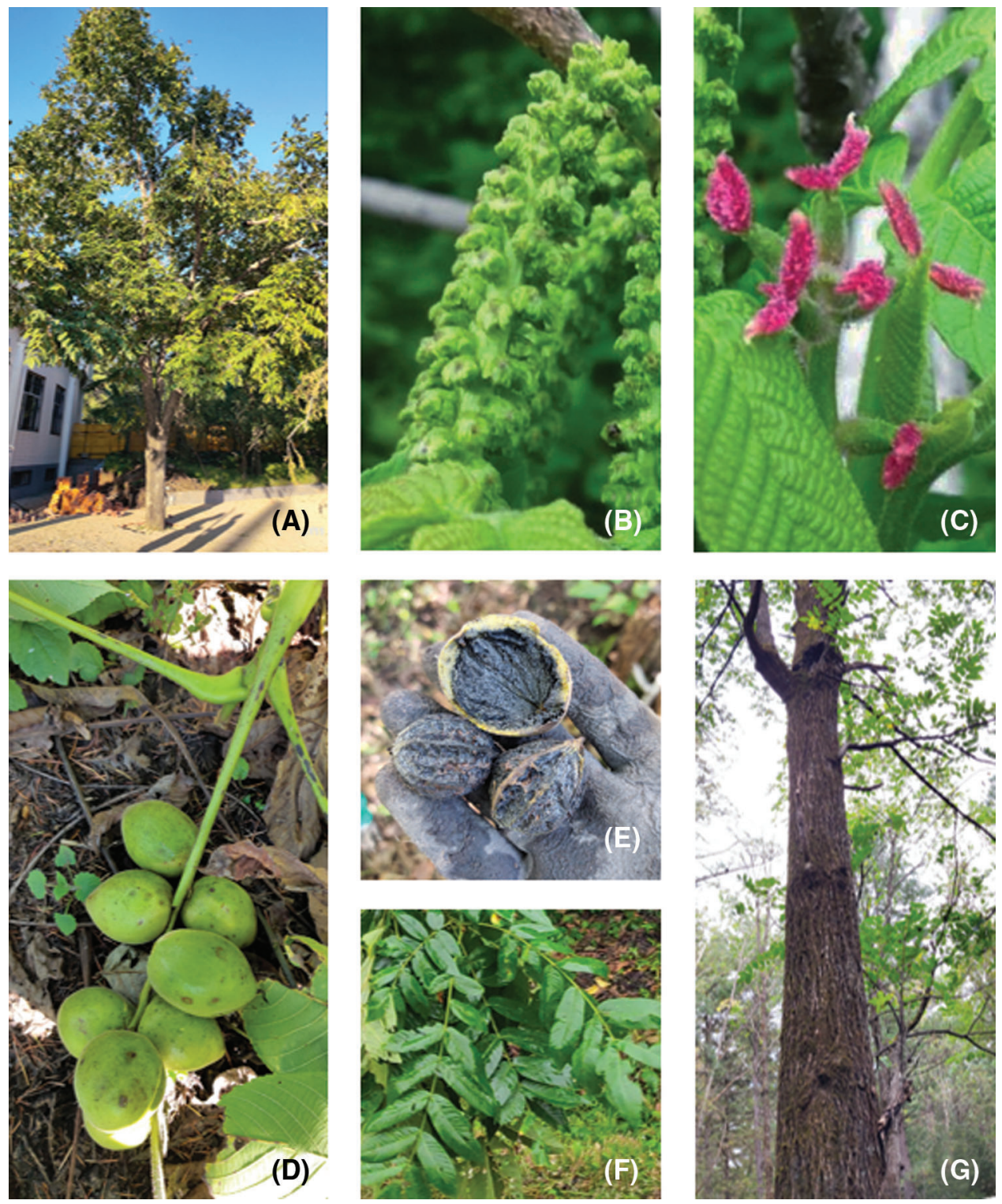

Figure 1: Morphological characteristics of $J$. mandshurica (A: Single plant; B: Male flowers; C: Female flowers; D: Fruits; E: Green peel and kernel; F: Leaves; G: Trunk) 
Research on the genetic improvement of $J$. mandshurica started in the 1980s and was mainly confined to conventional breeding. Some superior provenances and families were selected, and some wild germplasm resources were collected and preserved. However, due to the long breeding period, the research progress was relatively slow [18]. A handful of improved varieties was produced and seed orchards were established (Table 1), and few J. mandshurica varieties were cultivated. Strategies for research and protection of $J$. mandshurica populations have been extremely limited. With development in science and technology, molecular plant breeding techniques have been widely used in plant genetic improvement, while there have been only a few studies on molecular-assisted breeding in $J$. mandshurica, especially in recent years. People pay more attention to juglone due to its medicinal value, although the demand for $J$. mandshurica is increasing daily. Thus, there is an urgent need to cultivate high-quality $J$. mandshurica stock.

Table 1: Distribution of representative $J$. mandshurica improved variety bases and seed orchards

\begin{tabular}{llllll}
\hline Type & Codes & Location & Longitude (E) & Latitude (N) & Altitude $(\mathrm{m})$ \\
\hline Improved & Gangshan & Xinbin, Liaoning & $125^{\circ} 24^{\prime} 50^{\prime \prime}$ & $41^{\circ} 37^{\prime} 53^{\prime \prime}$ & 656 \\
varieties base & Liumao & Jixi, Heilongjiang & $130^{\circ} 47^{\prime} 07^{\prime \prime}$ & $45^{\circ} 14^{\prime} 30^{\prime \prime}$ & 210 \\
& Tieli & Tieli, Heilongjiang & $128^{\circ} 03^{\prime} 59^{\prime \prime}$ & $46^{\circ} 59^{\prime} 06^{\prime \prime}$ & 222 \\
\multirow{3}{*}{$\begin{array}{l}\text { Seed } \\
\text { orchard }\end{array}$} & Dailing & Yichun, Heilongjiang & $128^{\circ} 37^{\prime} 46^{\prime \prime}$ & $46^{\circ} 50^{\prime} 08^{\prime \prime}$ & 631 \\
& Linkou & Qingshan, Heilongjiang & $130^{\circ} 24^{\prime} 09^{\prime \prime}$ & $45^{\circ} 34^{\prime} 46^{\prime \prime}$ & 729 \\
& Baolongdian & Wuchang, Heilongjiang & $127^{\circ} 46^{\prime} 17^{\prime \prime}$ & $44^{\circ} 56^{\prime} 58^{\prime \prime}$ & 210 \\
& Linjiang & Linjiang, Jilin & $127^{\circ} 22^{\prime} 58^{\prime \prime}$ & $42^{\circ} 06^{\prime} 20^{\prime \prime}$ & 684 \\
\hline
\end{tabular}

Because of its high economic and ecological benefits, J. mandshurica has great potential for further research to develop high quality varieties. In this review, we summarized genetic improvement studies conducted to increase quality and yield of $J$. mandshurica through conventional and molecular breeding approaches. Gaps in genetic improvement were also identified and described, especially concerning medicinal substances, and new research strategies are formulated with different breeding goals for future research. This could provide a theoretical basis for the genetic improvement of $J$. mandshurica.

\section{Conventional Breeding}

\subsection{Studies for Selection of Improved Varieties}

In the process of tree breeding, the importance of improved varieties was unquestionable. Under the same geographical environment, improved varieties have higher genetic gains than unselected varieties, such as higher yields and greater resistance [19]. Generally, the improvement of superior varieties in forest trees mainly focuses on wood properties (latewood rate, basic density, fiber length, fiber width), fruit traits (high fruit yield and quality), growth traits (growth rate, tree height and DBH) or other traits to obtain high economic and ecological benefits. Currently, a variety of research methods, such as hybrid breeding [20], polyploid breeding [21,22], molecular breeding [23] and other research methods, have been used for further selection and breeding in improved varieties, which has produced many insightful results. However, researchers have mainly focused on conventional breeding to select improved $J$. mandshurica varieties [24-26]. The selection of provenances, families and clones facilitated the development of materials that accelerated the progress of genetic improvement for forest trees.

$J$. mandshurica is primarily distributed throughout Northeast China, it can also be found scattered throughout Nei Mongol, Beijing, Hebei, Shanxi, Henan, Shaanxi and other provinces (Fig. 2). Due to the local adaptation of $J$. mandshurica in these disparate environments, there are great differences in $J$. mandshurica among the various provenances. Thus, it is extremely important to carry out provenance tests, 
study geographical variation and select stable and high-yielding provenances for different locations. In $1985, J$. mandshurica seeds from eight provenances in Northeast China were collected and then used to carry out provenance tests. Two superior provenances (Kuandian and Shulan) were selected by comparative selection of growth traits, adaptive characteristics and morphological characteristics, whose genetic gain was $10.18 \%$. At the same time, it was determined that the growth and adaptability characteristics of $J$. mandshurica were significantly correlated with longitude and latitude [24]. Moreover, four important provenance districts (Wanda Mountains, low mountains in central Jilin Province, eastern Liaoning Province, Xiaoxinganling Mountains-Songhua River) for $J$. mandshurica were identified through correlation analysis [25]. After that, researchers mainly focused on studying the genetic variation in growth and seed or other traits of $J$. mandshurica, carrying out a further study of provenance. For example, Chu et al. [26] analyzed the tree height $(\mathrm{H})$ and diameter at breast height $(\mathrm{DBH})$ of $45 \mathrm{~J}$. mandshurica families (15 years) from three provenances and found that the coefficient of variation for $\mathrm{H}$ and $\mathrm{DBH}$ ranged from $35.6 \%$ to $45.35 \%$ and from $25.58 \%$ to $28.77 \%$, respectively, indicating that there were abundant variations within and among provenances. In addition to growth traits, fruit characteristics were also investigated, and six provenances (Hunchun, Dunhua, Jiaohe, Tonghua, Huinan and Fusong) were selected according to seed traits out of 14 provenances in Jilin Province [27]. Based on fruit and seed traits, 4 superior provenances (Sanchazi, Yabuli, Tieli and Jinshantun) and 53 superior individual plants were selected [28]. In addition, 15 excellent families (XL2, XL5, etc.) were selected according to seedling height and base diameter, 10 excellent families were selected by breeding value and other conditions, and 4 families (DC12, XB1, XB4 and FC8) were selected based on the independent culling method in which both average seedling height and ground diameter were $11.18 \%$ higher than those of the other families [3]. In another study, 59 superior individual plants of $J$. mandshurica in the Changbai Mountain area were selected according to three fruit characteristics: single fruit weight, kernel weight and kernel yield [29]. These superior provenances, families, and clones could be used as the preferred materials for the establishment of large-scale plantations.

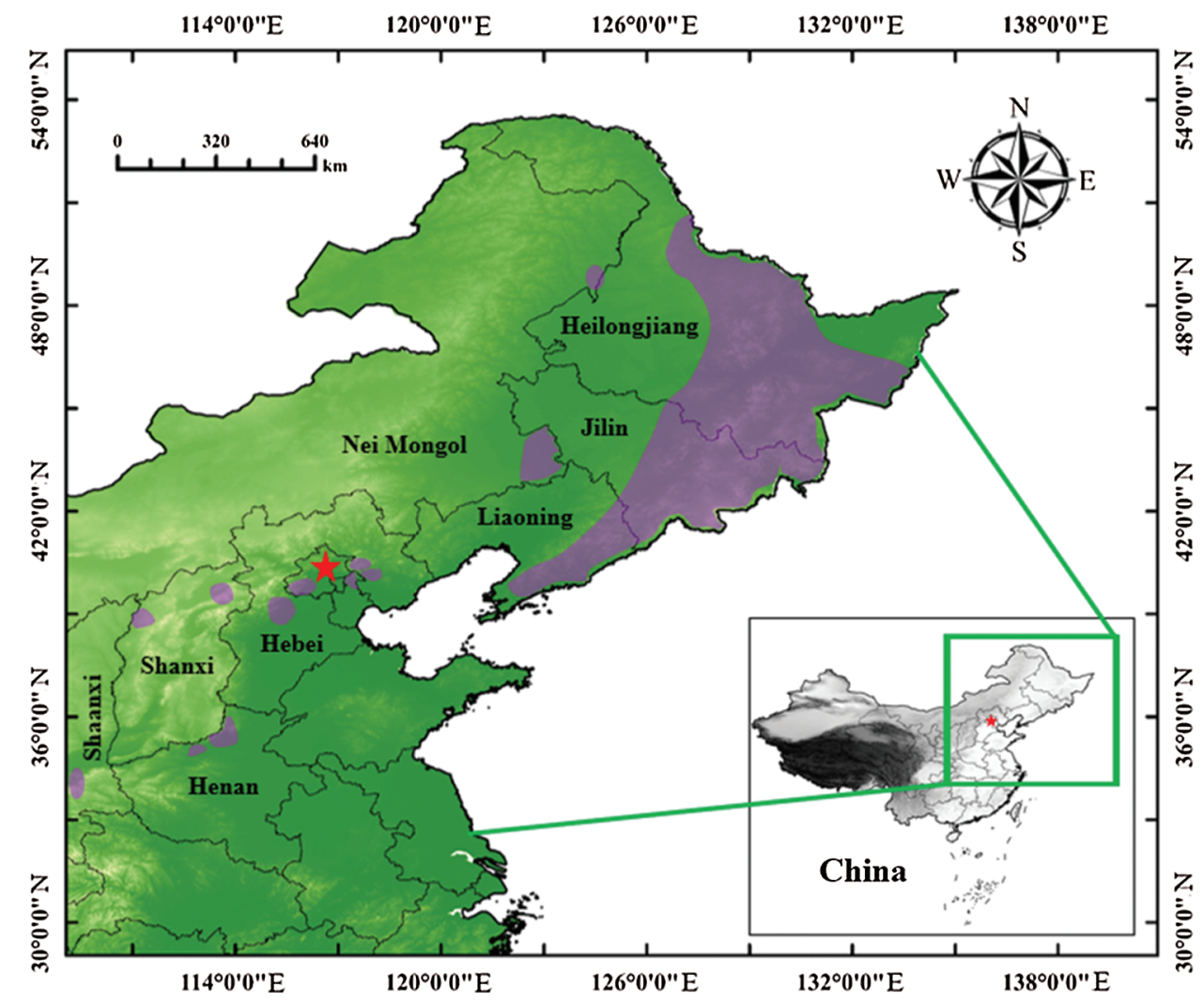

Figure 2: The main distribution areas of J. mandshurica in China 
As the natural environment is often complex and changeable, the growth indices of seedlings of $J$. mandshurica from different provenances were often greatly different after sowing in different locations. Some representative superior materials of $J$. mandshurica were selected according to different breeding objectives in previous studies (Table 2). In future research, these superior provenances could be used in the establishment of seed orchards, clonal afforestation and so on. At the same time, they could also provide a basis for hybrid breeding, radiation breeding and molecular breeding. Most importantly, previous studies showed that the provenance selection of $J$. mandshurica based on multiple traits was mainly concerned with growth traits and fruit characters, while the selection of medicinal value was not involved. In particular, the juglone contained in $J$. mandshurica had a significant effect on cancer treatment. Future studies on the medicinal value of $J$. mandshurica may have great potential and could become a hot topic. Therefore, research on improved varieties based on their medicinal value also needs appropriate attention.

Table 2: Some previous studies on genetic improvement of J. mandshurica

\begin{tabular}{|c|c|c|c|c|c|c|}
\hline Study level & $\begin{array}{l}\text { Total quantity } \\
\text { used for selection }\end{array}$ & $\begin{array}{l}\text { Afforestation } \\
\text { site }\end{array}$ & $\begin{array}{l}\text { Select } \\
\text { traits }\end{array}$ & $\begin{array}{l}\text { Tree } \\
\text { age }\end{array}$ & $\begin{array}{l}\text { Name of Superior Provenances/Improved } \\
\text { Varieties }\end{array}$ & References \\
\hline Provenance & 14 & $\begin{array}{l}\text { Changbai } \\
\text { Mountains }\end{array}$ & Fruit & unknown & $\begin{array}{l}\text { Hunchun Dunhua Jiaohe Tonghua Huinan } \\
\text { Fusong }\end{array}$ & [27] \\
\hline Provenance & 14 & Lushuihe & Growth & $1 \mathrm{a}, 2 \mathrm{a}$ & $4,14,13,5,8$ & {$[30]$} \\
\hline Provenance & 8 & Shangzhi & Growth & $1 \mathrm{a}$ & Shulan & {$[31]$} \\
\hline Family & 45 & Qingshan & Growth & $15 \mathrm{a}$ & $\begin{array}{l}\text { DC1, DC3, DC4, DC5, DC7, DC10, LQ7, } \\
\text { DC13, DC14 }\end{array}$ & {$[26]$} \\
\hline Family & 121 & $\begin{array}{l}\text { Liaoning } \\
\text { Province }\end{array}$ & Growth & $2 \mathrm{a}$ & KD10, QY6, QY31, QY19, QY33 & [32] \\
\hline Family & 39 & Fusong & Growth & $4 a$ & JM3, JM9, JM12, JM38 & {$[33]$} \\
\hline Family & 122 & Qingshan & Growth & $7 \mathrm{a}$ & $\begin{array}{l}\text { Y4, Y14, Y15, Y19, Y21, Y22, Y30, Y31, } \\
\text { T42, T44, T47, T54, M20 }\end{array}$ & [34] \\
\hline Clone & 55 & Taiyueshan & Growth & $5 \mathrm{a}$ & 1-6 Henan 1, Henan 2 & {$[35]$} \\
\hline
\end{tabular}

\subsection{Physiological Studies}

Light is one of the most indispensable environmental factors that affects plant growth and development. Photosynthetic indices also play a vital role in evaluating plant growth and can reveal the mechanisms of tree growth and development and environmental adaptability. At present, the main photosynthetic characteristics concerned by scientists in the process of plant breeding include net photosynthetic rate, stomatal conductance, transpiration rate, intercellular $\mathrm{CO}_{2}$ concentrations, leaf net $\mathrm{CO}_{2}$ assimilation rate and so on $[36,37]$. In past studies, plant photosynthetic indices were investigated in many species, such as Alnus cremastogyne Burk. [38], Pinus tabuliformis [39] and Populus tomentosa [40]. We reviewed the literature and found that there were some studies on the photosynthetic characteristics of J. mandshurica. Trees are often subjected to a variety of adverse environmental conditions, which result in different adverse effects on growth and development and can even lead to death. We have already explained that the distribution range of $J$. mandshurica is extremely wide under different natural conditions, and the growth environments are relatively diverse. In particular, some populations grow in damp, sunless gullies. The photosynthetic index of $J$. mandshurica was measured under three different light environments $(100 \%$, $60 \%$ and $30 \%$ ), indicating that the net photosynthetic rates of $J$. mandshurica were $16.88 \mu \mathrm{mol} \cdot \mathrm{m}^{-2} \cdot \mathrm{s}^{-1}$, $12.53 \mu \mathrm{mol} \cdot \mathrm{m}^{-2} \cdot \mathrm{s}^{-1}$ and $12.50 \mu \mathrm{mol} \cdot \mathrm{m}^{-2} \cdot \mathrm{s}^{-1}$, respectively [41]. Meanwhile, a similar conclusion emerged showing that $J$. mandshurica had strong adaptability and plasticity in different light environments $[42,43]$. In the seedling experiment, it was claimed that the chlorophyll content, net photosynthetic rate, 
transpiration rate and stomatal conductance of J. mandshurica decreased significantly with the deepening of drought stress. Drought seriously affects the physiological, biochemical and photosynthetic characteristics of $J$. mandshurica [18]. Thus, the study of the photosynthetic characteristics of $J$. mandshurica can provide important basic conditions for its high quality and yield.

Other physiological studies were also carried out, such as the content of malondialdehyde (MDA), catalase (CAT), peroxidase (POD) and superoxide dismutase (SOD) of seedlings growing under different soil moisture contents. The results indicated that cultivation of $J$. mandshurica is more appropriate when the soil moisture content was $70 \%$ to $75 \%$ of the field capacity, which the best treatment to save water during irrigation [44]. Additionally, endogenous hormones play an important role in regulating processes of plant growth and development. It was found that endogenous hormones, especially ethylene (ETH) and gibberellin (GA) contents, gradually increase during the development of $J$. mandshurica fruits, which have an important guiding significance for artificially controlling the ripening of walnut fruit [45].

\subsection{Asexual Propagation}

In the breeding techniques of $J$. mandshurica, some basic research on the technology of asexual propagation has been done [46,47], however, seed sowing is still the main method in the current tree breeding practice. The application of asexual propagation system needs to be strengthened. Sexual reproduction involves seeding, but the plant is prone to variation, and it is difficult to maintain the excellent characteristics of the parent plants. In asexual reproduction (also known as vegetative reproduction), some of the parent plants were used as reproductive material for cutting, grafting, tissue culture and more to form a new individual. The desirable characteristics of the parent plants can be more easily maintained through asexual reproduction, and the process is less time-consuming. Grafting experiments of $J$. mandshurica showed that the survival rate of double tongue grafting was as high as $83 \%$. The double tongue grafting method could obtain a larger contact surface after grafting and can make healing tissue growth faster [48]. A high-efficiency cutting system for J. mandshurica has also been established, with rooting rates of up to $82.2 \%$ [47,49]. In addition, plant tissue culture technology for $J$. mandshurica has also made a new breakthrough [50,51]. Browning was the greatest obstacle in $J$. mandshurica tissue culture, but new techniques have provided a solution. In one study, researchers showed that adding sodium thiosulfate and VC to the culture medium could effectively prevent the occurrence of browning [52]. Development in the asexual propagation of $J$. mandshurica could shorten the time of seedling cultivation and reduce material consumption and the influence of climate, and is thus conducive to the cultivation of high-quality seedlings for the market.

\section{Researches on Molecular Marker-Assisted Breeding}

With rapid development of molecular biology and sequencing technology in the 21st century, several molecular marker-assisted selection technologies, such as Restriction Fragment Length Polymorphism, Intersimple Sequence Repeat, Sequence-related Amplified Polymorphism, Random Amplified Polymorphic DNA, Amplified Fragment Length Polymorphism, Simple Sequence Repeats, Single Nucleotide Polymorphism, have been widely used in tree genetic breeding because of their high speed, intuitive use and low cost [53-56]. For example, fingerprints were constructed by SSR and ISSR markers in six clones of Populus deltoides Marsh., which provided a theoretical basis for species identification of poplar [57]; the accurate identification system of Eucalyptus germplasm resources was established by SSR [58]. There were similar applications in Citrus [59], Pinus tabuliformis Carr. [60], etc. Molecular marker-assisted breeding could play an extremely important role in the research fields of phylogenetics, genome-wide association studies (GWASs), gene bank construction, fingerprint construction, gene localization and so on, solving a large number of problems in the process of breeding research [61-63]. 
Based on molecular marker technology, recent research on $J$. mandshurica has focused mainly on genetic diversity, species identification, fingerprint and genetic structure or other aspects [64-66]. For example, Zhao et al. [67] established the optimal RAPD-PCR conditions for J. cinerea, J. ailantifolia, $J$. nigra, $J$. regia and $J$. mandshurica by polymerase chain reaction. The SRAP-PCR system of $J$. mandshurica was established for the first time and reported by Wang's research to construct successfully the fingerprint of 170 samples from 17 sampling points [68]. Then, the genetic diversity and genetic structure of $J$. mandshurica in 180 samples from six populations in different geographical distribution zones were explored successfully by ISSR technology, and 14 ISSR primers were selected. It was also found that $83.82 \%$ of the genetic variation existed within the population, and only a few variations existed in the interpopulation level [69]. Furthermore, this technology was also optimized in a better way, which will provide more convenience for further study on the genetic relationship and genetic diversity of $J$. mandshurica [70]. SSR technology was used to explore the genetic diversity of $J$. mandshurica, 20 pairs of SSR primers with more informative polymorphisms were developed, and it was determined that genetic variation mainly existed within population [71]. The genetic diversity of species or populations was due to long-term evolution, which is the most important prerequisite for the survival and evolution of any species. The higher the genetic diversity or genetic variation of a population or species is the better the ability to adapt to environmental changes and easier to expand the distribution range and exploit new environments to cope with the changing climate will be. The above studies have laid a rich theoretical foundation for the gene mapping of some important characteristics of $J$. mandshurica, including genetic diversity research, variety resource conservation, interspecific hybridization and phylogenetics.

\section{Medicinal Value}

The medicinal value of $J$. mandshurica has been increasing in recent years. Since ancient times, $J$. mandshurica has been known as a valuable traditional oriental medicine. Historically, the bark is steeped in water to make a tea. Studies on the constituents of $J$. mandshurica husks confirmed the existence of naphthoquinones [72], alkaloids [73], coumarin [74] and other compounds, which have a strong resistance to cancer cells and could therefore potentially be used in the treatment of cancer. This is especially true for the compound juglone, which has been proven through medical practice that it has extremely strong anticancer effects [75-77]. Moreover, the content of juglone is very high in $J$. mandshurica, especially in the green peel of its fruit. For some other diseases, some of the key substances in J. mandshurica still play an important role. Walnut hydrolyzed peptides (WHPs) obtained from the fruit proteins of $J$. mandshurica has an obvious effect on the treatment of diabetes [78]. Similar studies have shown that additional compounds in $J$. mandshurica have effective antibacterial and antioxidation properties and strengthen the immune system [79,80]. Although these studies have made some progress in understanding the chemical composition (Table 3) and pharmacological action of $J$. mandshurica, there has been little research on the genetic improvement of the medicinal characteristics of $J$. mandshurica.

Table 3: Contents of some useful substances in J. mandshurica

\begin{tabular}{llll}
\hline Name of the material & Subordinate part & Contents & References \\
\hline Anthraquinones & Green peel & $3.25 \%$ & {$[81]$} \\
& Leaves & $2.10 \%$ & \\
Juglone & Leaves & $5.00 \%$ & {$[82]$} \\
& Barks & $4.17 \%$ & \\
& Green peel & $3.05 \%$ & \\
& Stem & $3.83 \%$ & {$[83]$} \\
\hline
\end{tabular}




\begin{tabular}{llll}
\hline \multicolumn{1}{c}{ Table 3 (continued) } & & & \\
\hline Name of the material & Subordinate part & Contents & References \\
\hline Quercetin & Barks & $0.28 \%$ & {$[84]$} \\
Triterpenoids & Green peel & $2.62 \%$ & {$[13]$} \\
Total flavonoids & Barks & $2.20 \%$ & {$[85]$} \\
Protein & Kernel & $34.349 \%$ & {$[86]$} \\
Oil & Kernel & $56.42 \%$ & {$[86]$} \\
Unsaturated fatty acids & Kernel oil & $96 \%$ & {$[87]$} \\
\hline
\end{tabular}

\section{Other Studies on $J$. mandshurica}

With the rapid development of the global economy, countries around world are facing a very serious energy challenge. The development of renewable energy plays a very important role in sustainable development of the national economy. Wood oil plants are becoming an important energy source due to their unique biological characteristics and significant utilization value [88]. The study showed that the oil extracted from the seed kernel of $J$. mandshurica is as high as $60.08 \%$ [89]. This demonstrated that the kernel of $J$. mandshurica has great oil production potential. At the same time, the edible value of trees, as an important part of the dietary value, has important economic significances. It is therefore important to select and breed superior $J$. mandshurica varieties with edible or oil characteristics.

Another crucial issue is diseases and pest control in the forest breeding process. Diseases and pest control are an important part of forestry production to ensure stable yields and economic benefits and to maintain the ecological environment. In this regard $J$. mandshurica could be useful as extracts from leaves, exocarp and bark of $J$. mandshurica have been shown effective against many kinds of agricultural and forestry pests $[90,91]$. The tree still has some natural disease and is susceptible to pest invasion, such as walnut melanconis disease, Dictyoploca japonica Moore., Caligula boisduvalifallax Jordan., and Pandemisdumetana Treitschke [92]. In general, the application of forest pest control measures has weak effects and high cost. Therefore, selecting and breeding elite varieties that can resist pests and disease is a better way to prevent the diseases and can genetically improve $J$. mandshurica.

\section{Research Gaps and Future Directions}

Research on the genetic improvement of $J$. mandshurica was reported decades ago. However, until now, the research progress has been slow, and the main achievements in genetic improvement were provenance tests, family selection, seed orchard construction and part of the plant molecular genetic improvement. However, there were many key aspects that were not well studied, such as further collection and evaluation of germplasms, selection based on multiple traits, and the molecular mechanism of some key physiological and biophysical characteristics.

\subsection{Germplasm Resources, Seed Orchards and Improved Variety Bases}

Germplasm resources refer to many propagation materials that can be used in forest tree breeding. It is the most crucial material base for forest breeding, especially for cultivating new superior varieties and exploring the origin and evolution of species. In the past, J. mandshurica was harvested heavily because of its excellent wood and medicinal value. Thus, the wild germplasm resources of $J$. mandshurica have substantially declined and the species is currently listed as the third class nationally protected plant in China. Fortunately, collection and preservation of germplasm resources of $J$. mandshurica has started in recent years; for instance, the germplasm resources in eastern Liaoning Province of J. mandshurica were 
collected. Researchers studied the variability of fruits and screened the fruit to distinguish the different morphological types; three of these (spherical, one-tip-spherical, two-tip-spherical) could be selected as the planting types and cultivated [68]. In future, concerted efforts should be made to further collect and evaluate wild germplasm resources within the natural distribution area of $J$. mandshurica.

In addition, establishment of seed orchards and improved variety bases can play a crucial role in the genetic improvement of forest trees. It not only provides convenience for the collection and transportation of seeds but also maintains the characteristics of excellent trees to improve the genetic quality of seeds. Moreover, it can quickly provide a huge number of experimental materials to obtain improved varieties with high genetic gain [93]. The existence of seed orchards provides greater convenience for genetic improvement studies and speeds up the process of seed improvement. As seeds of $J$. mandshurica collected from the wild have low genetic gain coupled with unstable seed yield and poor seed quality, it could not satisfy the actual needs for afforestation in the northeast forest region. Therefore, it is urgent to establish additional seed orchards to provide basic research materials, which then enables establishment of good seed bases based on multiple trait selection, especially for medicinal traits.

\subsection{Molecular Breeding}

In 2018, whole-genome sequencing of $J$. mandshurica was completed. The entire genome assembly was $558 \mathrm{Mb}$ long (coverage $=145 \times)$ and contained 13810 scaffolds $(\mathrm{N} 50=496.9 \mathrm{~kb})$ [94]. However, the draft genomes were not yet sufficient for future research. In a recent study, a high-quality chromosome-level genome of $J$. mandshurica was reported with a genome size of $548 \mathrm{Mb}$ (contig N50 $=6.49$, scaffold N50 $=36.4 \mathrm{Mb}$ ) [95]. Hence, high-quality genome assembly and annotation of draft genomes by thirdgeneration sequencing and Hi-C will help to better reveal some of the biological characteristics of $J$. mandshurica and to aid the process of genetic improvement by targeted genetic engineering technology. For example, improving fruit yield [96] or disease resistance [97] and other traits of great significance to forest production practices will enable higher economic benefits. However, molecular breeding studies in J. mandshurica are still scarce now. Genome-wide association studies, SNP marker development and mapping, QTL location, and resequencing studies have still yet to be carried out for $J$. mandshurica. However, the chloroplast DNA of $J$. mandshurica has been sequenced, and the reference chloroplast genome of $J$. mandshurica has been preliminarily constructed [98]. Chloroplast genome sequencing of $J$. mandshurica would provide strong support for fruit yield, resistance, pharmaceuticals, wood quality improvement and many other traits. Furthermore, chloroplast genome research also has great significance in the exploration of photosynthesis mechanisms and metabolic regulation of J. mandshurica.

Gene mapping for specific traits of $J$. mandshurica has not been performed, especially for genes related to medicinal substances, such as the synthesis of juglone. As the most important medicinal substance in $J$. mandshurica that could treat cancer [99], the synthesis mechanism of juglone is still unclear. Research on breeding for improved variety of medicinal value could become a new direction for genetic improvement of $J$. mandshurica in future. In addition, with the development of other molecular breeding techniques, such as transcriptomics, metabolomics and proteomics, future research could lead to breakthroughs to explore the molecular mechanism of medicinal substance formation. Furthermore, transgenic technology has been widely used in forestry research; for example, transgenic poplars are endowed with a toxic protein gene and eventually become resistant to diseases and pests [100]. However, transgenic research on some special genes and breeding targets has not been done in J. mandshurica. Therefore, the use of genetic engineering technology to improve $J$. mandshurica and produce new varieties could enable overcoming the limitation of species and interspecies hybridization bottlenecks to create new traits or varieties adapted to production. 


\subsection{Multiple-Traits Comprehensive Evaluation and Selection}

Different breeding objectives in tree genetic improvement determined different breeding and selection methods [101]. For instance, to meet the demand of wood in the early stage of genetic improvement of $J$. mandshurica, the selection and breeding of improved varieties was mainly based on growth and seed traits, aiming to cultivate high-quality and fast-growing varieties to expand its wood economic benefits. Subsequently, with the development of the national economy, society has put new requirements for the development of forest research. Therefore, the multiple-trait selection of forest trees gained increasing research interest. Moreover, J. mandshurica also has other valuable economic traits, such as medicinal, wood and fruit traits. Previous studies have detected and identified more than 400 constituents from different plant parts of $J$. mandshurica that have medicinal potential [102], including quinones, flavonoids, steroids, triterpenoids, phenolics and more. Consequently, aiming at specific medicinal substances, the selection and breeding for the development of improved varieties of $J$. mandshurica with higher medicinal substance contents can create greater value. Some studies have shown that the content of juglone, which has the highest medicinal value, was very high in the fruit green peel of $J$. mandshurica. Therefore, it is necessary the focus on the selection and breeding towards increasing fruit yield. Because of the widely useful and excellent wood characteristics of $J$. mandshurica, it has become very popular in the wood market. Therefore, to obtain faster growth and better wood quality, it is particularly important to improve the growth and wood characteristics as much as possible in forest genetic breeding research on $J$. mandshurica. In addition, the development of other economic value of $J$. mandshurica needs to be strengthened, such as its artistic value. The kernel of the native $J$. mandshurica in northeast China was small and had many shapes. It does not reach the same high antique value as Juglans regia, which belongs to the same genus, Juglans [103].

\subsection{Hybrid Breeding and Ploidy Breeding}

We have already shown that $J$. mandshurica has many excellent characteristics, such as good wood properties, high medicinal value and nutritious fruits. However, except for its high wood utilization rate, other characteristics have not been developed to a high degree. Therefore, according to the current social needs in research on the genetic improvement of $J$. mandshurica, it is important to solve the problems of small seeds, low fruiting and low content of medicinal substance.

The goal of hybrid breeding is to obtain offspring with the desired traits of both the male and female parents [104]. This breeding method plays an important role in the creation of new genotypes and has added significantly to the economic value of poplars [105], eucalyptus [106] and more. In addition, polyploid breeding strengthens some traits or weakened other traits [107]. For example, the new polyploid rice was created by chromosome doubling, cross breeding and self-breeding, which increased rice productivity and quality [108]. Similarly, because the fruit of natural $J$. mandshurica in Northeast China was relatively small, the fruit yield was low, while $J$. mandshurica from Hebei had larger fruits and higher yields. High fruit yielding $J$. mandshurica trees that could be suitable for cultivation in the northeast could be obtained by crossing. The increase in fruit yield due to hybridization, in turn, enhances the medicinal value as juglone is mostly found in the green peel of the fruit. Chromosome doubling provides an opportunity for the breeding of improved varieties with high medicinal substance content as it might double the medicinal substance content. Therefore, the application of cross breeding and ploidy breeding is advised for improving varieties of $J$. mandshurica with large seeds, high yield, high content of medicinal substances and rapid growth. 


\section{Conclusions and Recommendations}

$J$. mandshurica, a native broad-leaved species in northeast China with immense ecological and economic benefits. It plays an extremely important role in wood, food production, medicine, landscaping and other purposes. Some achievements have been made through conventional breeding and molecular breeding, and some superior provenances and families have been selected. However, the breeding goals of $J$. mandshurica have mainly focused on growth traits in past research, which need more attention towards its medicinal substances. Related breeding methods, such as cross-breeding or ploidy breeding, have not been carried out, and the creation of germplasm resources of $J$. mandshurica based on new breeding goals has been still relatively slow. Moreover, molecular breeding should be emphasized. Due to the lack of high-quality genome sequencing data, some crucial studies of J. mandshurica, such as molecular evolution, gene composition or gene regulation, cannot be carried out. These key studies will allow future research into traits needed to shorten the breeding cycle of this species.

Finally, we suggested genetic improvement strategies for $J$. mandshurica by combining the existing research findings and considering future research directions (Fig. 3). As a first step, further collection and evaluation of germplasm is necessary to capture as much genetic variation as possible. Using hybrid breeding, ploidy breeding and selective breeding of these new germplasm collections, improved varieties with good growth, wood quality and fruit yield will be selected. For selecting improved varieties for higher medicinal contents of $J$. mandshurica, the newly collected germplasms should undergo selection based on molecular marker-assisted breeding, ploidy breeding and genetic engineering technologies. These studies could provide new insight for genetic improvement research on $J$. mandshurica. Combining conventional breeding with molecular breeding, the cycle of genetic improvement would be greatly shortened and both the accuracy and process of genetic improvement in J. mandshurica will be greatly increased.

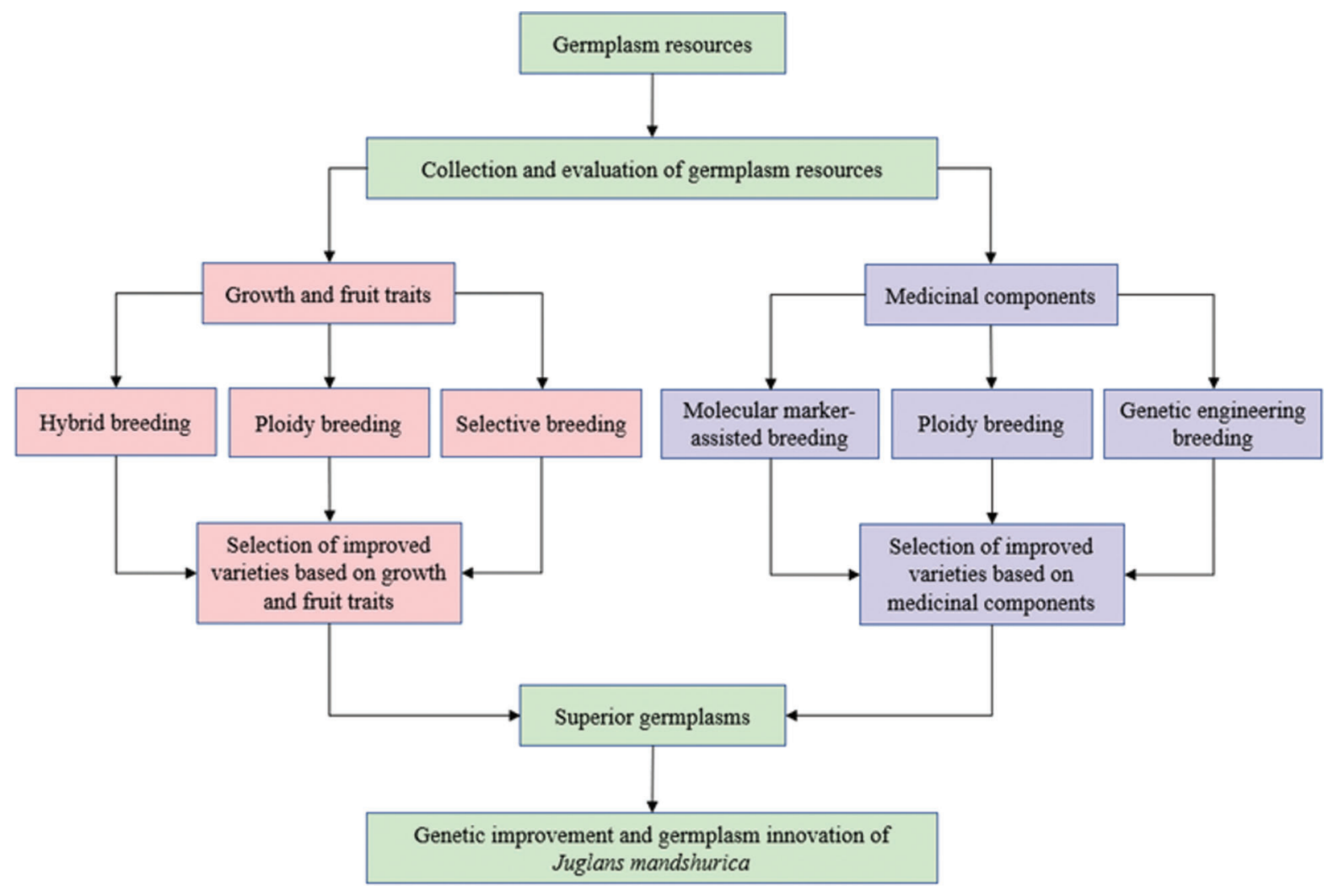

Figure 3: Genetic improvement strategies for J. mandshurica 
Funding Statement: This research was funded by the Scientific Research Start-Up Funds of Jilin Agricultural University (No. 2021002).

Conflicts of Interest: The authors declare that they have no conflicts of interest to report regarding the present study.

\section{References}

1. Zhang, X. L., Liu, C., Liu, J., Zhang, X., Cheng, G. L. (2019). Research status and breeding strategy of Juglans mandshurica. Journal of Jilin Forestry Science and Technology, 48(1), 14-17. DOI 10.16115/j.cnki.issn.10057129.2019.01.004.

2. Luo, Y., Ji, L., Yang, Y. C., Wang, J., He, H. J. et al. (2020). Tree species composition and diversity of secondary mixed forests of juglans mandshurica in northeast China. Chinese Journal of Ecology, 39(9), 2887-2895. DOI 10.13292/j.1000-4890.202009.017.

3. Yuan, X. L., Qi, Y. H., Liu, Z. L., Zhou, Z. J., Mao, Z. J. (2013). Provenance selection of Juglans mandshurica Maxim and the effects of environmental factors. Bulletin of Botanical Research, 33(4), 468-476. DOI 10.7525/j. issn.1673-5102.2013.04.014.

4. Zhang, L. J., Guo, C., Lu, X. J., Sun, X. M., Liu, C. P. et al. (2021). Flower development of heterodichogamous Juglans mandshurica (Juglandaceae). Frontiers in Plant Science, 12, 541163. DOI 10.3389/FPLS.2021.541163.

5. Zhang, L. J., Guo, C., Qin, B., Lu, X. J., Yang, Y. C. et al. (2019). Phonological characteristics of flowering and pollen viability of Juglans mandshurica. Journal of North-East Forestry University, 47(5), 4-8. DOI 10.13759/j. cnki.dlxb.2019.05.002.

6. Li, J. N., Gao, R. X. (2020). Research progress on the genetic breeding of juglans mandshurica in China. Journal of Anhui Agricultural Science, 48(17), 4-7. DOI 10.3969/j.issn.0517-6611.2020.17.002.

7. Hao, L. C. (2015). Research on the effects of juglans mandshurica maxim as rootstock on some physiological characteristics and quality of 'Lvling' Juglans regia. L. (Ph.D. Thesis). Agricultural University of Hebei, Hebei.

8. Liu, Z. H., Ma, X. H., Xie, Q. (2019). Wood anatomy of Juglans regia, J. cathayensis and J. mandshurica. Journal of Northeast Forestry University, 47(6), 49-52. DOI 10.13759/j.cnki.dlxb.2019.06.009.

9. Zhu, L. G., Zhang, J., Xu, F. C. (2018). Variation regularity on 9 families of Juglans mandshurica in Heihe. Forest by-Product and Speciality in China, 6, 41-42+44. DOI 10.13268/j.cnki.fbsic.2018.06.013.

10. Song, J., Li, J., Guo, C., Zhou, Y., Wang, H. (2017). Selection of fruit variation type of juglans mandshurica germplasm resources in the eastern liaoning mountain region. Molecular Plant Breeding, 15(9), 3798-3802. DOI 10.13271/j.mpb.015.003798.

11. Pei, X. N., Zhang, Q. H., Zhang, S. K., Wang, D., Kong, L. Y. et al. (2020). Variation analysis of leaf characters of Juglans mandshurica clones. Molecular Plant Breeding, 19(6), 1-11. DOI 10.13271/j.mpb.019.002030.

12. Zhou, Y. Y., Song, H. J., Guo, S., Wang, Y., Gao, H. R. et al. (2019). A new triterpene from the green walnut husks of Juglans mandshurica Maxim. Journal of Natural Medicines, 73(4), 800-804. DOI 10.1007/s11418019-01309-4.

13. Guo, Y. X., Sun, M. L. (2020). Extraction of triterpenoids from the green peel of juglans mandshurica maxim and its antibacterial activity. Forest Engineering, 36(3), 37-43. DOI 10.16270/j.cnki.slgc.2020.03.006.

14. Huo, J. H., Du, X. W., Sun, G. D., Dong, W. T., Wang, W. M. (2018). Identification and characterization of major constituents in Juglans mandshurica using ultra performance liquid chromatography coupled with time-of-flight mass spectrometry (UPLC-eSI-q-tOF/MS). Chinese Journal of Natural Medicines, 16(7), 525-545. DOI 10.1016/ S1875-5364(18)30089-X.

15. Yan, M. X., Wang, Q. Q., Yang, M. Z., Xue, W. J., Shi, L. et al. (2020). Antioxidant activity in vitro of total flavonoids from cortex Juglandis mandshurica. Contemporary Chemical Industry, 49(6), 1051-1055. DOI 10.13840/j.cnki.cn21-1457/tq.2020.06.011.

16. Jin, M., Sun, J. F., Li, R., Diao, S. B., Zhang, C. H. et al. (2016). Two new quinones from the roots of juglans mandshurica. Archives of Pharmacal Research, 39(9), 1237-1241. DOI 10.1007/s12272-016-0781-1. 
17. Luo, Y., Yang, Y. C., Wang, J., Ji, L., Liu, T. et al. (2019). Site index model of Juglans mandshurica natural secondary mixed forest in Changbai Mountain Area, Jilin Province, China. The Journal of Applied Ecology, 30(12), 4049-4058. DOI 10.13287/j.1001-9332.201912.008.

18. Ji, L., Han, J., Wang, F., Wang, J., Song, D. et al. (2019). Effects of drought stress on photosynthetic and physiological characteristics of Juglans mandshurica seedlings in different soil substrates. Bulletin of Botanical Research, 39(5), 722-732. DOI 10.7525/j.issn.1673-5102.2019.05.011.

19. Zhai, Y. (2014). Populus clonal breeding (Master Thesis). Shandong Agricultural University, Taian.

20. Shiranifar, B., Hobson, N., Kebede, B., Yang, R., Rahman, H. (2021). Potential of rutabaga (Brassica napus var. napobrassica) gene pool for use in the breeding of hybrid spring brassica napus canola. Plant Breeding, 140(2), 305-319. DOI 10.1111/pbr.12895.

21. Chen, R. R., Feng, Z. Y., Zhang, X. H., Song, Z. J., Cai, D. T. (2021). A new way of rice breeding: Polyploid rice breeding. Plants-Basel, 10(3), 422. DOI 10.3390/plants10030422.

22. Zhang, H. Y., Zhu, X. W., Hou, P. Q., Hu, R. F., Huang, X. et al. (2019). Research progress and prospect of fruit tree haploid and polyploid. Molecular Plant Breeding, 17(2), 606-611. DOI 10.13271/j.mpb.017.000606.

23. Savadi, S., Muralidhara, B. M., Preethi, P. (2020). Advances in genomics of cashew tree: Molecular tools and strategies for accelerated breeding. Tree Genetics \& Genomes, 16(5), 196-209. DOI 10.1007/s11295-02001453-z.

24. Yang, S. W. (1991). The further study on the geographic variation of Juglans mandshurica. Journal of Northeast Forestry University, 19(S2), 183-188. DOI 10.13759/j.cnki.d1xb.1991.s2.029.

25. Liu, G. F. (1991). The primary division and selection for the optimal provenance of Juglans mandshurica. Journal of Northeast Forestry University, 19(S2), 189-196. DOI 10.13759/j.cnki.d1xb.1991.s2.030.

26. Chu, X. L., Zhu, H. Y., Zhang, H. G., Zhang, L., Zhang, Z. (2010). Variation among provenances and families of Juglans mandshurica and preliminary selection. Journal of Northeast Forestry University, 38(11), 5-6+14. DOI 10.13759/j.cnki.dlxb.2010.11.014.

27. Chen, S. Y., Yang, H., Han, J., Zhang, D. W., Zhao, S. S. et al. (2015). Provenance variation of seed traits of Juglans mandshurica in Changbai Mountains, Northeastern China. Journal of Beijing Forestry University, 37(12), 32-40. DOI 10.13332/j.1000-27.1522.20150278.

28. Zhang, H. X., Li, A., Zhang, H. G., Zhang, L., Zhang, J. B. (2017). Juglans mandshurica fruits and seeds variation and plus tree selection. Journal of Northeast Forestry University, 45(3), 1-7. DOI 10.13759/j.cnki. dlxb.2017.03.001.

29. Wang, J., Yang, Y. C., Zhang, R., Yang, B., Yu, H. Y. et al. (2020). Study on the selection and preservation the superior individuals' fruit characters of Juglans mandshurica in Changbai Mountain Area. Journal of Jilin Forestry Science and Technology, 49(3), 1-3+7. DOI 10.16115/j.cnki.issn.1005-7129.2020.03.001.

30. Zhao, S. S., Zhang, D. W., Xu, Y. G., Yang, H., Lin, S. J. et al. (2016). The research of different provenance seedling growth of Juglans mandshurica. Journal of Jilin Forestry Science and Technology, 45(1), 4-9. DOI 10.16115/j.cnki.issn.1005-7129.2016.01.002.

31. Xia, D. A., Xu, Z. Z., Hou, D., Zhou, J., Wang, H. R. (2014). Study on genetic variation law of Juglans mandshurica provenances. Journal of Anhui Agricultural Sciences, 42(31), 10956-10958.

32. Yan, T. W., Yu, S. H., Wang, Q. C., He, L., Feng, J. (2020). Differences in seedling growth among half-sibling families of Juglans mandshurica in liaoning area. Liaoning Forestry Science and Technology, (6), 13-15. DOI 10.13989/j.cnki.0517-6611.2014.31.047.

33. Han, Y. X., Wu, L., Yu, Q., Hua, C., Yang, Y. C. et al. (2020). Variation analysis on growth traits of 39 Juglans mandshurica families. Journal of Jilin Forestry Science and Technology, 49(6), 1-4. DOI 10.16115/j.cnki. issn.1005-7129.2020.06.001.

34. Zhang, H. G., Deng, J. F., Zhang, L., Xu, Y. L. (2011). Variation regularity among provenances of Juglans mandshurica and family selection. Journal of Northwest Forestry College, 28(2), 91-95.

35. Wang, J. Y. (2017). Selection of excellent clones of Juglans mandshurica Taihang Mountain. Protection Forest Science and Technology, (7), 63-65. DOI 10.13601/j.issn.1005-5215.2017.07.023. 
36. Cai, L. P., Wu, P. F., Hou, X. L., Ma, X. Q., Zhang, Y. (2011). Effects of drought stress on photosynthetic characteristics of pioneer plant Neyraudia reynaudiana on soil and water conservation. Journal of Soil and Water Conservation, 25(6), 237-241+259. DOI 10.13870/j.cnki.stbcxb.2011.06.012.

37. Jia, H., Guo, F., Wu, Y., Yao, B., Wang, Y. et al. (2016). The variance analysis of photosynthetic characteristic parameters of different Paulownia Clones. Journal of Henan Agricultural University, 50(2), 176-180+188. DOI 10.16445/j.cnki.1000-2340.2016.02.006.

38. Liu, S. L., Ma, M. D., Pan, Y. Z., Wei, L. L., He, C. X. et al. (2012). Effects of light regimes on photosynthetic characteristics and antioxidant system in seedlings of two alder species. Chinese Journal of Plant Ecology, 36(10), 1062-1074. DOI 10.3724/SP.J.1258.2012.01062.

39. Gao, Q., Wang, W. Y., Liang, D., Li, Y. (2014). Comparison of growth traits and photosynthetic physiology in Pinus tabuliformis from eight provenances of China. Journal of Beijing Forestry University, 36(2), 87-93.DOI 10.13332/j.cnki.jbfu.2014.02.018.

40. Yang, Z. X., Feng, M. A. K., Ming, Z., Liang, B. J., Yan, J. W. et al. (2011). Comparative analysis of the photosynthetic characteristics of three-year-old Populus tomentosa clones. Forest Research, 24(3), 370-378. DOI 10.13275/j.cnki.lykxyj.2011.03.020.

41. Zhang, D. L., Zhang, L., Ge, W. Z. (2017). Phenotypic plasticity and respond of Juglans mandshurica seedling under different light environments. Bulletin of Botanical Research, 37(5), 658-663. DOI 10.7525/j.issn.16735102.2017.05.004.

42. Chen, D. P., You, J. H., Liu, D. D., Wang, X. Y., Li, Y. et al. (2018). A comparative study on evolutionary structures of the Juglans mandshurica in different ecological environment stress. Journal of Northeast Normal University, 50(2), 97-102. DOI 10.16163/j.cnki.22-1123/n.2018.02.018.

43. Wang, K., Zhu, J. J., Yu, L. Z., Sun, Y. R., Zhang, J. X. (2010). Effects of light environment on Juglans mandshurica seedlings growth and photosynthesis. The Journal of Applied Ecology, 21(4), 821-826. DOI 10.13287/j.1001-9332.2010.0149.

44. Yao, N. E., Peng, Z. D., Li, C. L., Liu, Y. (2020). Effects of soil water on the growth and physiological characteristics of juglans mandshurica seedlings. Journal of Irrigation and Drainage, 39(S1), 1-6. DOI 10.13522/j.cnki.ggps.2020066.

45. Qin, B. T., Cai, J. Y., Fu, J. Q., Liu, C. P., Zhang, L. J. (2021). Dynamic changes of endogenous hormones in juglans mandshurica during sex differentiation. Molecular Plant Breeding, 1-9. http://kns.cnki.net/kcms/detail/ 46.1068.S.20210301.1528.015.html.

46. Zhang, J. Y., Yin, D. S., Ge, W. Z., Tian, X. H., Li, J. et al. (2019). Pretreatment explants from mature embryos of adventitious bud induction for Juglans mandshurica maxim. Journal of Northeast Forestry University, 47(2), 2124. DOI 10.13759/j.cnki.dlxb.2019.02.005.

47. Ge, W. Z., Qi, Y. H., Liu, J. M., Yao, Y., Yin, D. S. et al. (2015). Technique of green-wood cutting propagation of Juglans mandshurica maxim. Journal of Anhui Agricultural Sciences, 43(23), 143-146. DOI 10.13989/j. cnki.0517-6611.2015.23.057.

48. Xiao, Y. P., Liu, H. W., Zhang, S. H. (2015). A preliminary report on grafting experiment of Juglans mandshurica. Forest by-Product and Speciality in China, (6), 47-48. DOI 10.13268/j.cnki.fbsic.2015.06.016.

49. Song, J. X., Li, J., Guo, C., Zhou, Y. C., Wang, H. et al. (2017). Selection of fruit variation type of Juglans mandshurica germplasm resources in the Eastern Liaoning Mountain Region. Molecular Plant Breeding, 15(9), 3798-3802. DOI 10.13271/j.mpb.015.003798.

50. Qiu, X. M. (2014). Technology of tissue culture and rapid propagation of Juglans mandshurica maxim. Journal of Inner Mongolia Forestry Science and Technology, 40(2), 29-30+64.

51. Zhang, J. Y., Qi, Y. H., Lv, Y. D., Liu, J. M., Xing, Y. J. (2015). Regeneration system for axillary bud of Juglans mandshurica maxim. Bulletin of Botanical Research, 35(1), 22-26. DOI 10.7525/j.issn.1673-5102.2015.01.005.

52. Li, J., Wang, S. T., Zhou, Q., Yang, C. Y., Qi, Y. H. et al. (2020). Preliminary study on browning mechanism of Juglans mandshurica stem in tissue culture. Molecular Plant Breeding, 1-8.

53. Liu, L., Liu, G., Gong, Y., Dai, W., Wang, Y. et al. (2007). Evaluation of genetic purity of F-1 hybrid ISSR, seeds in cabbage with RAPD, SRAP and SSR Markers. Hortscience, 42(3), 724-727. DOI 10.21273/HORTSCI.42.3.724. 
54. Tan, Z., Li, Y., Hu, Q., Mei, D., Cheng, J. (2008). Advances in molecular marker techniques for heterosis application in rapeseed. Chinese Bulletin of Botany, 25(2), 230-239.

55. Wang, C., Qiao, A., Fang, X., Sun, L., Gao, P. et al. (2019). Fine mapping of lycopene content and flesh color related gene and development of molecular marker-assisted selection for flesh color in watermelon (Citrullus lanatus). Frontiers in Plant Science, 10, 1240. DOI 10.3389/fpls.2019.01240.

56. Yang, R., Piao, Z., Wan, C., Lee, G., Ruan, X. et al. (2020). Breeding for three-line japonica hybrid rice combinations with high resistant starch content using molecular marker-assisted selection. Breeding Science, 70(3), 409-414. DOI 10.1270/jsbbs.20005.

57. Li, W. (2014). SSR and ISSR fingerprints identification and application in New varieties (clones) from the Populus deltoides (Populaceae) (Master Thesis). Northwest Agriculture and Forestry University, Yanglin.

58. Liu, G., Xie, Y. J. (2012). Application of molecular marking technologies in heredity breeding of eucalyptus. World Forestry Research, 25(3), 19-25. DOI 10.13348/j.cnki.sjlyyj.2012.03.010.

59. Gulsen, O., Uzun, A., Canan, I., Seday, U., Canihos, E. (2010). A new citrus linkage map based on SRAP, SSR, ISSR, POGP, RGA and RAPD markers. Euphytica, 173(2), 265-277. DOI 10.1007/s10681-010-0146-7.

60. Yang, H. X., Luo, R., Zhao, F. C., Liu, T. Y., Liu, C. X. (2013). Constructing genetic linkage maps for Pinus elliottii var. elliottii and Pinus caribaea var. Hondurensis Using SRAP, SSR, EST and ISSR Markers. Trees, 27(5), 14291442. DOI 10.1007/s00468-013-0890-0.

61. Guo, Y. S., Zhao, Y. H., Liu, C. J., Ren, P. R., Huang, T. L. et al. (2009). Construction of a molecular genetic linkage map for longan based on RAPD, ISSR, SRAP and AFLP markers. Acta Horticulturae Sinica, 36(5), 141-148. DOI 10.16420/j.issn.0513-353x.2009.05.006.

62. Hazarika, T. K., Hazarika, B. N., Shukla, A. C. (2014). Genetic variability and phylogenetic relationships studies of genus citrus L. with the application of molecular markers. Genetic Resources and Crop Evolution, 61(8), 14411454. DOI 10.1007/s10722-014-0188-0.

63. Li, X., Li, M., Hou, L., Zhang, Z. Y., Pang, X. M. et al. (2018). De novo transcriptome assembly and population genetic analyses for an endangered Chinese endemic acer miaotaiense (Aceraceae). Genes, 9(8), 378. DOI 10.3390/genes9080378.

64. Chen, C. M., Han, S. J., Yuan, S. S., Wang, C. J., Yu, J. H. (2013). Isolation and characterization of 20 polymorphic microsatellite markers for Juglans mandshurica (Juglandaceae). Applications in Plant Sciences, 1(7), 1200009. DOI 10.3732/apps.1200009.

65. Zhang, H., Hu, D. C., Xie, X. M., Liu, D., Zhang, P. et al. (2020). Analyses on population structure and genetic diversity of Juglans mandshurica in Queshan Provincial Nature Reserve of Shandong. Journal of Plant Resources and Environment, 29(3), 34-42. DOI 10.3969/j.issn.1674-7895.2020.03.05.

66. Liu, H., Chen, C., Di, X., Zhang, H., Kang, T. G. et al. (2020). HPLC fingerprint analysis of Juglans mandshurica root based on UHPLC-q-tOF-mS/MS. Modern Chinese Medicine, 22(6), 862-870+878. DOI 10.13313/j. issn.1673-4890.20190925003.

67. Zhao, P., Zhao, G. F., Zhang, S. X., Zhou, H. J., Hu, Y. H. et al. (2014). RAPD derived markers for separating manchurian walnut (Juglans mandshurica) and Japanese walnut (Juglans ailantifolia) from close congeners. Journal of Systematics and Evolution, 52(1), 101-111. DOI 10.1111/jse.12059.

68. Wang, Y. (2007). The study on the genetic diversity of Juglans mandshurica maxim in the northeast of China (Master Thesis). Northeast Forestry University, Harbin.

69. Wang, D. N. (2011). Studies on genetic diversity and genetic structure of Juglans mandshurica Maxim natural population (Master Thesis). Northeast Forestry University, Harbin.

70. Wang, S. T. (2020). Establishment and optimization of ISSR molecular marker system for natural forest of Juglans mandshurica in Eastern Liaoning Area. Molecular Plant Breeding, 19(1), 1-11. DOI 10.13271/j.mpb.019.002286.

71. Liu, J. Z. (2015). Based on the analysis of species distribution model of juglans mandshurica genetic diversity and virtual screening of flavonoids compounds in Juglans mandshurica (Master Thesis). Northeast Forestry University, Harbin. 
72. Zhou, Y. Y., Yang, B. Y., Jiang, Y. Q., Liu, Z. X., Liu, Y. X. et al. (2015). Studies on cytotoxic activity against hepG-2 cells of naphthoquinones from green walnut husks of Juglans mandshurica maxim. Molecules, 20(9), 15572-15588. DOI 10.3390/molecules200915572.

73. Lou, L. L., Cheng, Z. Y., Guo, R., Yao, G. D., Song, S. J. (2019). Alkaloids from juglans mandshurica maxim induce distinctive cell death in hepatocellular carcinoma cells. Natural Product Research, 33(6), 1-4. DOI 10.1080/14786419.2017.1413571.

74. Lou, L. L., Zhao, P., Cheng, Z. Y., Guo, R., Yao, G. D. et al. (2019). A new coumarin from juglans mandshurica maxim induce apoptosis in hepatocarcinoma cells. Natural Product Research, 33(12), 1791-1793. DOI 10.1080/ 14786419.2018.1434646.

75. Ji, Y. B., Qu, Z. Y., Zou, X. (2011). Juglone-induced apoptosis in human gastric cancer SGC-7901 cells via the mitochondrial pathway. Experimental and Toxicologic Pathology, 63(1-2), 69-78. DOI 10.1016/j. etp.2009.09.010.

76. Aithal, B. K., Kumar, M. R. S., Rao, B. N., Udupa, N., Rao, B. S. S. (2009). Juglone, a naphthoquinone from walnut, exerts cytotoxic and genotoxic effects against cultured melanoma tumor cells. Cell Biology International, 33(10), 1039-1049. DOI 10.1016/j.cellbi.2009.06.018.

77. Wang, P. (2019). Molecular mechanism of autophagy and apoptosis of human hepatocellular carcinoma cells induced by jugone from juglans mandshurica maxim (Ph.D. Thesis). Northeast Forestry University, Harbin.

78. Wang, J., Du, K. Y., Fang, L., Liu, C. L., Min, W. H. et al. (2018). Evaluation of the antidiabetic activity of hydrolyzed peptides derived from juglans mandshurica maxim fruits in insulin-resistant hepg2 cells and type 2 diabetic mice. Journal of Biochemistry, 42(3), e12518. DOI 10.1111/jfbc.12518.

79. Yang, Q., Yao, Q. S., Kuang, Y., Zhang, Y. Z., Feng, L. L. et al. (2019). Antimicrobial and cytotoxic juglones from the immature exocarps of juglans mandshurica. Natural Product Research, 33(22), 1-7. DOI 10.1080/ 14786419.2018.1468326.

80. Li, J., Wang, J., Liu, C. L., Fang, L., Min, W. H. (2018). Protein hydrolyzates from changbai mountain walnut (Juglans mandshurica maxim.) boost mouse immune system and exhibit immunoregulatory activities. Evidence-Based Complementary and Alternative Medicine, (5), 1-10. DOI 10.1155/2018/4576561.

81. Wu, M. (2019). Extraction and isolation of active components from green peel of juglans mandshurica maxim and their activity (Master Thesis). Northeast Forestry University, Harbin.

82. Sun, M. L., Song, Z. Q., Fang, G. Z. (2006). Extraction and determination of total flavonoid and juglone in juglans mandshurica maxim. Chemistry and Industry of Forest Products, 26(2), 93-95.

83. Wang, T. M., Zhai, Y. J., Xu, S. Z., Chen, H. B., Kang, T. G. (2012). Study on the dynamic variation of juglone content in the branches of juglans mandshurica. Chinese Journal of Hospital Pharmacy, 32(15), 1166-1168. DOI 10.13286/j.cnki.chinhosppharmacyj.2012.15.001.

84. Lei, T., Meng, F. Q., Wu, Y. Y. (2012). Quantitative determination of quercetin of cortex juglandis mandshuricae in mudanjiang. Laboratory Science, 15(1), 88-90. DOI 10.3969/j.issn.1672-4305.2012.01.028.

85. Meng, L. H., Chang, L., Lei, T., Wu, Y. Y. (2011). Determination of flavonoids in juglandis mandshuricae cortex. Journal of Mudanjiang Medical University, 32(5), 5-7. DOI 10.13799/j.cnki.mdjyxyxb.2011.05.019.

86. Yu, Y. Y. (2012). The protein extracted and antihypertensive peptides preparation from the kernel of juglans mandshurica maxim (Master Thesis). Northeast Forestry University, Harbin.

87. Su, J. L. (2008). The study on extraction, stability and reduce bloodlipi of juglans mandshurica maxim oil (Master Thesis). Northeast Forestry University, Harbin.

88. Zheng, T., Gou, G. Q., He, X. Z., Ye, H. H., Fu, W. (2019). Investigation and analysis of wild woody oil plant resources in Jiangkou County. Guizhou Province. China Oils and Fats, 44(6), 106-110.

89. Ning, Y., Lin, L. J., Wang, F. J. (2014). Extraction of manchurian walnut oil assisted by ultrasonic and fatty acid composition. Food Science and Technology, 39(10), 184-188. DOI 10.13684/j.cnki.spkj.2014.10.039.

90. Wang, X. M., Shi, D. F., Liu, C. M., Yu, C. L., Qu, S. X. et al. (2016). Toxicity of extract from juglans mandshurica maxim leaves on two species of natural enemies. Journal of Northeast Forestry University, 44(7), 91-93. DOI 10.13759/j.cnki.dlxb.2016.07.019. 
91. Sun, M. L., Song, Z. Q., Fang, G. Z. (2007). Insecticidal activity and active components of alcohol extract from juglans mandshurica maxim leaves. The Journal of Applied Ecology, 18(12), 2910-2914. DOI 10.13287/j.10019332.2007.0461.

92. Cai, W. L., Gao, Y., Li, H. F. (2010). Main diseases and pests of Juglans mandshurica and its control techniques. Modern Agricultural Sciences and Technology, (24), 162-164.

93. Wang, Z. R. (2019). The enlightenment from advanced breeding experience abroad to the development advancedgeneration seed orchard construction in China. Journal of Nanjing Forestry University (Natural Sciences Edition), 43(1), 161-166. DOI 10.3969/j.issn.1000-2006.201711048.

94. Bai, W. N., Yan, P. C., Zhang, B. W., Woeste, K. E., Lin, K. et al. (2018). Demographically idiosyncratic responses to climate change and rapid pleistocene diversification of the walnut genus Juglans (Juglandaceae) revealed by whole-genome sequences. New Phytologist, 217(4), 1726-1736. DOI 10.1111/nph.14917.

95. Yan, F., Xi, R. M., She, R. X., Chen, P. P., Yan, Y. J. et al. (2021). Improved de novo chromosome-level genome assembly of the vulnerable walnut tree Juglans mandshurica reveals gene family evolution and possible genome basis of resistance to lesion nematode. Molecular Ecology Resources, 21(6), 2063-2076. DOI 10.1111/17550998.13394.

96. Unamba, C. I. N., Nag, A., Sharma, R. K. (2015). Next generation sequencing technologies: The doorway to the unexplored genomics of non-model plants. Frontiers in Plant Science, 6, 1074. DOI 10.3389/fpls.2015.01074.

97. Zhang, S. J., Chen, W. P., Xin, L., Gao, Z. H., Hou, Y. J. et al. (2014). Genomic variants of genes associated with three horticultural traits in apple revealed by genome re-sequencing. Horticulture Research, 1(1), 14045. DOI 10.1038/hortres.2014.45.

98. Hu, Y. H. (2018). Phylogenetic and population genetics of juglandaceae based on genomics and transcriptomics (Master Thesis). Northwest University, Xi'an.

99. Zhao, X. Y., Song, X. X., Zhao, J. R., Zhu, W. H., Hou, J. C. et al. (2019). Juglone inhibits proliferation of hpvpositive cervical cancer cells specifically. Biological and Pharmaceutical Bulletin, 42(3), 475-480. DOI 10.1248/ bpb.b18-00845.

100. Ding, L. P., Chen, Y. J., Wang, H. Z., Wei, J. H. (2018). Efficacy of Cry1Ac protein against gypsy moth and fall webworm in transgenic poplar (Populus davidiana $\mathrm{x}$ Populus bolleana) by bioassay. Canadian Journal of Plant Science, 98(4), 844-850. DOI 10.1139/cjps-2017-0322.

101. Wang, F., Wang, Q., Zhao, X. Y. (2019). Research progress of phenotype and physiological response mechanism of plants under low temperature stress. Molecular Plant Breeding, 17(15), 5144-5153. DOI 10.13271/j. mpb.017.005144.

102. Luan, F., Wang, Z. Y., Yang, Y., Ji, Y. F., Lv, H. Z. et al. (2021). Juglans mandshurica maxim.: A review of Its traditional usages, phytochemical constituents, and pharmacological properties. Frontiers in Pharmacology, 11, 569800. DOI 10.3389/FPHAR.2020.569800.

103. Sun, X. L. (2012). Research on traditional walnut culture and its leisure agriculture development (Master Thesis). Nanjing Agricultural University, Nanjing.

104. Yao, J. X., Li, H. G., Ye, J., Shi, L. L. (2016). Relationship between parental genetic distance and offspring's heterosis for early growth traits in liriodendron: Implication for parent pair selection in cross breeding. New Forests, 47(1), 163-177. DOI 10.1007/s11056-015-9508-2.

105. Li, S. W., Zhang, Z. Y., He, C. Z., An, X. M. (2004). Progress on hybridization breeding of poplar in China. World Forestry Research, 17(2), 37-41. DOI 10.13348/j.cnki.sjlyyj.2004.02.010.

106. Fu, C. Y. (2019). Study on the adaptability and genetic differences of 15 hybrid eucalyptus (Master Thesis). Guangxi University, Nanning.

107. Griffin, A. R., Nghiem Quynh, C., Harbard, J. L., Do Huu, S., Harwood, C. E. et al. (2015). Breeding polyploid varieties of tropical acacias: Progress and prospects. Southern Forests: A Journal of Forest Science, 77(1), 41-50. DOI 10.2989/20702620.2014.999303.

108. Zhang, X. H., Zuo, B., Song, Z. J., Wang, W., He, Y. C. et al. (2017). Breeding and study of two new photoperiodand thermo-sensitive genic male sterile lines of polyploid rice (Oryza sativa L.). Scientific Reports, 79(1), 959966. DOI 10.1038/s41598-017-15241-8. 